\title{
Effect of acute stress on oesophageal motility in patients with gastro-oesophageal reflux disease
}

\author{
B T Johnston, R J McFarland, J S A Collins, A H G Love
}

\begin{abstract}
Background and aim-Sixty four per cent of people with heartburn believe that it is exacerbated by stress. An alteration in oesophageal motility is one possible mechanism for this apparent change with stress. This study aimed to assess the effect of acute stressors on oesophageal motility in patients with gastrooesophageal reflux disease (GORD).

Methods-Sixty patients were studied. Twenty had oesophagitis, 20 had increased oesophageal acid exposure on pH monitoring but no endoscopic oesophagitis, and 20 had neither oesophagitis nor abnormal oesophageal acid exposure. Oesophageal motility was studied in these patients during psychological stress (Stroop test) and physical stress (cold pressor test).
\end{abstract}

Results-Blood pressure (BP) and heart rate increased in response to both stressors (mean systolic BP increased by $>10 \mathrm{~mm} \mathrm{Hg}$, diastolic BP by $>4 \mathrm{~mm} \mathrm{Hg}$ and heart rate by $>3$ beats per minute $(p<0 \cdot 00001)$. The amplitude, duration, and velocity of propagation of oesophageal peristaltic contractions were not altered by the stressors. The percentage of simultaneous waves increased in patients with oesophagitis during the cold pressor test (median increase in these patients was $6 \%(p<0.05))$. This effect was not noted in the patients without oesophagitis. Conclusion-Acute stressors did not induce significant changes in oesophageal motility in patients with GORD but no oesophagitis. For these patients, dysmotility is not likely to be a cause of oesophageal symptoms which are exacerbated by stress. There was, however, a significant increase in simultaneous waves during cold pressor stress in patients with oesophagitis.

(Gut 1996; 38: 492-497)

Keywords: cold pressor test, gastro-oesophageal reflux disease, oesophageal motility, Stroop colour-word test, stress, psychological.

Meparticinent of

Victoria Hospital,

Belfast and Ulster

Hospital, Dundonald

B T Johnston

R J McFarland

J S A Collins

A H G Love

Correspondence to: Dr B T Johnston, Lagan Valley Hospital, Hillsborough Road, Lisburn, Co Antrum BT28 1JP.

Accepted for publication 23 October 1995

Gastro-oesophageal reflux disease (GORD) has generally been regarded as a well understood disorder with an established pathophysiological basis. When known pathogenic factors such as the presence or absence of a hiatus hernia and measures of lower oesophageal sphincter (LOS) and oesophageal motility function, have been assessed, however, they have at best predicted only $13-26 \%$ of the variability seen in the range of results of oesophageal $\mathrm{pH}$ monitoring. ${ }^{12}$ It is also recognised that symptoms are not a good predictor of GORD as defined by oesophagitis or abnormal oesophageal acid exposure on $\mathrm{pH}$ monitoring. ${ }^{3} 4$

Sixty four per cent of people with heartburn attribute a worsening of their symptoms to stress. ${ }^{5}$ Stress has long been known to affect oesophageal function - early studies reported spasm in response to emotional upset in patients with cardiospasm. $^{6}$ Studies using more modern equipment have documented oesophageal motility changes in response to stressors in healthy volunteers ${ }^{78}$ and patients with pre-existing oesophageal dysmotility abnormalities, such as nutcracker oesophagus. ${ }^{9}$ To our knowledge, no study of the oesophageal motility response to stress in GORD has been published. If stressors were to induce simultaneous or non-conducted contractions in GORD patients, these changes could delay the clearance of acid from the oesophagus, exacerbating reflux symptoms. This study aimed to assess the effect of acute stressors on oesophageal motility in patients with GORD.

\section{Methods}

Sixty patients with heartburn and reflux symptoms who were attending their local hospital for the first time because of heartburn were studied. None had previously undergone upper gastrointestinal investigation or surgery and none had been taking anti-reflux therapy or any medication that might alter oesophageal motility for at least two weeks before investigation. Patients who were pregnant, who consumed $>60 \mathrm{~g} /$ day alcohol, or had a disorder such as diabetes or scleroderma that could alter oesophageal motility were excluded.

Twenty consecutive patients falling into each of three groups were studied. The three groups were as follows:

- Endoscopic oesophagitis, defined as linear or confluent erosions or ulceration ${ }^{10}$;

- No oesophagitis and no other mucosal abnormalities on endoscopy but abnormal oesophageal acid exposure as measured by ambulatory $\mathrm{pH}$ monitoring $(\mathrm{pH}+)$;

- Both a normal endoscopy and $\mathrm{pH}$ moni-
Ambulatory oesophageal $\mathrm{pH}$ monitoring was performed for a minimum of 18 hours, with an antimony electrode placed $5 \mathrm{~cm}$ above the manometrically determined lower oesophageal sphincter (LOS). pH readings were recorded onto a digital monitor (Digitrapper, Synectics Medical, Enfield, UK) 
and displayed and stored on an IBM compatible computer. Patients were classified as having abnormal oesophageal acid exposure if their total time of $\mathrm{pH}<4$ in the distal oesophagus exceeded $4 \cdot 7 \%$. This value is the 95 th centile of total time $\mathrm{pH}<4$ for normal subjects in our laboratory. ${ }^{11}$

After an overnight fast, manometry was performed using a low compliance capillary infusion pump (Arndorfer Inc, Milwaukee, Wisconsin, USA) and an eight channel polyvinyl catheter with orifices spaced at $3 \mathrm{~cm}$ intervals and a $6 \mathrm{~cm}$ sleeve device. Five individual channels were connected to external transducers and the analogue output from these transducers was converted to a digital signal using a Digitrapper (Synectics Medical, Enfield, UK). These pressure tracings were displayed and stored on an IBM compatible computer. Pressures were recorded from the LOS by a sleeve device and from the oesophagus, 2 and $5 \mathrm{~cm}$ above the upper border of the LOS. A pressure sensor was placed on the neck at the level of the cricoid cartilage to act as a swallow marker. A period of 20 minutes was allowed for the patient to become accustomed to the tube before testing.

The stressors used in this study were the Stroop colour-word test (a psychological stressor) and the cold pressor test which is predominantly a physical stressor. During the Stroop test incongruous colour-word combinations, for example the word 'red' printed in green ink, were shown to the subject. These combinations are randomly generated onto a computer screen and the subject asked in random order either to name the word or the colour of ink in which it was printed. The stressor has previously been shown to induce anxiety, physiological changes including increases in heart rate and systolic blood pressure, and an increase in plasma adrenaline concentrations in normal subjects. ${ }^{12}$ During the cold pressor test, ${ }^{13}$ the patient immersed his or her left hand in crushed ice for periods of 60 seconds, removing it for 15 second intervals between each immersion. This sequence of hand immersion was repeated for the duration of a series of water swallows consisting of at least ten $5 \mathrm{ml}$ boluses.

A minimum of ten $5 \mathrm{ml}$ boluses of water were delivered to the patient's mouth via syringe at 20 second intervals for each of four periods (until eight peristaltic sequences had been recorded ${ }^{14}$ ): two rest periods (rest 1 and rest 2), and two stress periods (Stroop and ice). Rest 1 was followed by Stroop and rest 2 by ice immersion with a 20 minute break after Stroop, before starting the rest 2 period. Systolic (SBP) and diastolic (DBP) blood pressure and heart rate (HR) were recorded every 90 seconds using an Accutorr $1 \mathrm{~A}$ noninvasive blood pressure and pulse monitor (Datascope Corporation, Paramus, NJ, USA). The mean values of SBP, DBP, and HR for each of the four periods were calculated. At the end of each period, the subject was asked to indicate on a visual analogue scale, the degree of subjective stress experienced during that period $(0=$ no stress, $10=$ extremely stressful).
Distal oesophageal contraction amplitude was measured as the average of the amplitudes recorded 2 and $5 \mathrm{~cm}$ above the LOS for each swallow. Distal oesophageal contraction duration was calculated in the same manner. Propagation velocity was measured as the time difference between the onset of contractions 2 and $5 \mathrm{~cm}$ above the LOS.

The oesophageal contractile response to swallowing was interpreted by computer algorithm (Gastrosoft Inc, Irving, TX, USA) as simultaneous if propagation velocity was greater than $10 \mathrm{~cm} / \mathrm{s}$, as non-conducted if the contraction amplitude at $2 \mathrm{~cm}$ or $5 \mathrm{~cm}$ above the LOS was $<30 \mathrm{~mm} \mathrm{Hg}$, or else as peristaltic. Mean values for all peristaltic contraction sequences were calculated. Swallows resulting in simultaneous or non-conducted contractions were counted and expressed as a percentage of all swallows during that period. LOS pressure was assessed as the mean reading of the sleeve device over the 10 seconds preceding a swallow. Lower oesophageal sphincter pressure preceding each of 10 swallows was averaged to provide a mean LOS pressure for each study period.

To determine if stress affected BP, HR, and oesophageal motility, paired $t$ tests were performed between the values recorded during the stress period and during the respective rest periods for all measurements, with the exception of the ratings on the visual analogue scale and the percentages of nonperistaltic waves. Since the values for these latter two measurements were not normally distributed, the Wilcoxon signed rank test was used for these comparisons. In addition, the difference between the values recorded in the stress period and the rest period were calculated for each variable and compared. This difference is referred to as the delta value. This value made it possible to determine if the stress response differed between the three groups. Analysis of variance was used to compare these delta values between the three groups (the Kruskal-Wallis ANOVA being used for ratings on the visual analogue scale and the percentages of non-peristaltic waves). When a significant $F$ ratio for group differences was found, the Newman-Keuls test was used to determine which of the groups differed in their responses. This study was approved by the Research Ethics Committee of the Queen's University of Belfast.

\section{Results}

The mean ages of the three groups were similar (oesophagitis 47 years, $\mathrm{pH}+46$ years and $\mathrm{pH}-43$ years). There were more men in the oesophagitis group $(70 \%)$ than in the $\mathrm{pH}+$ group $(40 \%)$ and the $\mathrm{pH}-$ group $(35 \%)$, and this difference was statistically significant (Cochrane-Mantel-Haenszel $\left.\chi^{2}=4.82, \mathrm{p}<0.028\right)$. Both stressors induced highly significant changes in BP and HR and in VAS ratings (Tables I and II). The changes did not differ between the groups. 
TABLE I Effect of Stroop test on cardiovascular variables and patients' ratings of stress on the visual analogue scale (A) Summary of the results for each variable at rest (Rest 1) and during the test for all 60 patients*

\begin{tabular}{lllll}
\hline & Rest 1 & Stroop & & \\
\hline & Mean (SEM) & Mean (SEM) & $\mathrm{t}(\mathrm{df}, 59)$ & $p$ \\
Systolic blood pressure (mm Hg) & $132 \cdot 4(2 \cdot 2)$ & $142 \cdot 7(2 \cdot 4)$ & $8 \cdot 5$ & $<0 \cdot 00001$ \\
Diastolic blood pressure (mm Hg) & $78 \cdot 2(1 \cdot 4)$ & $83 \cdot 0(1 \cdot 7)$ & $5 \cdot 0$ & $<0 \cdot 00001$ \\
Heart rate (/min) & $74 \cdot 6(1 \cdot 4)$ & $80 \cdot 3(1 \cdot 3)$ & $6 \cdot 5$ & $<0 \cdot 00001$ \\
& Median (IQR) & Median (IQR) & $Z(d f, 59)$ & $p$ \\
Visual analogue scale (0-10) & $1(1-2)$ & $5(3-7)$ & $6 \cdot 4$ & $<0 \cdot 00001$
\end{tabular}

(B) Comparison of the delta values (differences between the results for Stroop and Rest 1) for each group $\dagger$

\begin{tabular}{|c|c|c|c|c|c|}
\hline & Oesophagitis & $p H+$ & $p H-$ & & \\
\hline $\begin{array}{l}\text { Systolic blood pressure }(\mathrm{mm} \mathrm{Hg}) \\
\text { Diastolic blood pressure }(\mathrm{mm} \mathbf{H g}) \\
\text { Heart rate }(/ \mathrm{min})\end{array}$ & $\begin{array}{c}\text { Mean (SEM) } \\
10.2(1 \cdot 8) \\
3.8(1.4) \\
4.8(1 \cdot 2)\end{array}$ & $\begin{array}{l}\text { Mean (SEM) } \\
11.8(1.8) \\
6.8(1.8) \\
6.6(1.6)\end{array}$ & $\begin{array}{l}\text { Mean (SEM) } \\
9 \cdot 0(2 \cdot 7) \\
3 \cdot 8(1 \cdot 8) \\
5.8(1 \cdot 8)\end{array}$ & $\begin{array}{l}F(d f, 2,57) \\
0.43 \\
1.03 \\
0.34\end{array}$ & $\begin{array}{l}p \\
\text { NS } \\
\text { NS }\end{array}$ \\
\hline Visual analogue scale $(0-10)$ & $\begin{array}{l}\text { Median (IQR) } \\
4(3-6 \cdot 5)\end{array}$ & $\begin{array}{l}\text { Median (IQR) } \\
3(2-6 \cdot 5)\end{array}$ & $\begin{array}{l}\text { Median (IQR) } \\
2(1 \cdot 5-5)\end{array}$ & $\begin{array}{l}H \\
2 \cdot 49\end{array}$ & $\stackrel{p}{N S}$ \\
\hline
\end{tabular}

$\mathrm{IQR}=$ interquartile range, $\mathrm{df}=$ degrees of freedom, $\mathrm{H}=$ Kruskal-Wallis $\mathrm{H}$ statistic.

$\star$ Results compared using paired $t$ test and Wilcoxon signed rank test, as described in Methods.

tANOVA, as described in Methods.

Amplitude, duration, and propagation velocity of contractions were not significantly altered by either of the stressors (Table III). Although contraction amplitude, velocity of propagation, and LOS pressure were higher during the Stroop test, none of these differences reached statistical significance. Nor was there any difference between the groups in their response to the stressors with regard to peristaltic variables.

There was a significant increase in the percentage of simultaneous waves during the cold pressor test (Table IV). Kruskal-Wallis analysis of variance showed that the groups responded to the ice test differently, and Newman-Keuls tests showed that the patients with oesophagitis responded to the ice test differently from the patients in the other two groups with regard to an increase in simultaneous waves. In a total of seven $(35 \%)$ patients with oesophagitis and four $(10 \%)$ without oesophagitis (two from each group) the number of simultaneous waves in response to ice increased by $10 \%$ of more (odds ratio 4.8 , $\mathrm{p}<0.05)$. This increase in simultaneous waves was 35\% (7 of 20) sensitive and 90\% (36 of 40) specific for oesophagitis patients.

\section{Discussion}

This is the first study to report the oesophageal motility response to stress in patients with GORD. The results show that acute stressors, both psychological and physical, have little effect on oesophageal motility in these patients. The only difference noted during stress was an increase in simultaneous waves in patients with oesophagitis in response to the cold pressor test. This increase in non-peristaltic waves is similar to that shown in normal subjects by others. Stacher et al reported simultaneous waves in response to acoustic stimuli in all volunteers when a sufficiently intense stimulus was applied. ${ }^{8}$ Ayres et al noted a significant increase to a mean of $34 \%$ simultaneous waves during the cold pressor test in healthy volunteers. ${ }^{7}$ A simultaneous wave shown manometrically corresponds to a contraction occurring at the same time throughout the distal oesophagus and in radiological studies has been associated with ineffective clearance of the oesophagus. ${ }^{1516}$ There are several possible reasons why this response was more often found in those with oesophagitis. Firstly, the oesophagitis group comprised significantly more males and it is known that

TABLE II Effect of cold pressor test (ice) on cardiovascular variables and patients' ratings of stress on the visual analogue scale

(A) Summary of the results for each variable at rest (Rest 2) and during ice test for all 60 patients

\begin{tabular}{lllll}
\hline & Rest 2 & Ice & & \\
\hline & Mean (SEM) & Mean (SEM) & $\mathrm{t}($ df,59) & $p$ \\
Systolic blood pressure (mm Hg) & $130 \cdot 8(2 \cdot 2)$ & $144 \cdot 7(2 \cdot 3)$ & $11 \cdot 4$ & $<0 \cdot 00001$ \\
Diastolic blood pressure (mm Hg) & $77 \cdot 5(1 \cdot 5)$ & $83 \cdot 8(1 \cdot 7)$ & $5 \cdot 8$ & $<0 \cdot 00001$ \\
Heart rate (/min) & $74 \cdot 4(1 \cdot 3)$ & $77 \cdot 9(1 \cdot 3)$ & $5 \cdot 9$ & $<0 \cdot 00001$ \\
& Median (IQR) & Median (IQR) & $Z(d f, 59)$ & $p$ \\
Visual analogue scale (0-10) & $1(0-1)$ & $5(3-8)$ & $6 \cdot 3$ & $<0 \cdot 00001$
\end{tabular}

(B) Comparison of the delta values (differences between the results for Ice and Rest 2) for each groupt

\begin{tabular}{|c|c|c|c|c|c|}
\hline & Oesophagitis & $p H+$ & $p H-$ & & \\
\hline $\begin{array}{l}\text { Systolic blood pressure }(\mathrm{mm} \mathrm{Hg}) \\
\text { Diastolic blood pressure }(\mathrm{mm} \mathrm{Hg}) \\
\text { Heart rate (/min) }\end{array}$ & $\begin{array}{c}\text { Mean (SEM) } \\
11 \cdot 9(2 \cdot 2) \\
5 \cdot 8(2 \cdot 2) \\
3 \cdot 2(1 \cdot 1)\end{array}$ & $\begin{array}{c}\text { Mean (SEM) } \\
15 \cdot 1(2 \cdot 3) \\
7 \cdot 8(1 \cdot 8) \\
3 \cdot 7(1 \cdot 1)\end{array}$ & $\begin{array}{c}\text { Mean (SEM) } \\
14.8(1.9) \\
5.2(1.7) \\
3.6(1.0)\end{array}$ & $\begin{array}{l}F(d f, 2,57) \\
0.69 \\
0.56 \\
0.06\end{array}$ & $\begin{array}{l}p \\
\text { NS } \\
\text { NS } \\
\text { NS }\end{array}$ \\
\hline Visual analogue scale $(0-10)$ & $\begin{array}{l}\text { Median }(I Q R) \\
3.5(1-7)\end{array}$ & $\begin{array}{l}\text { Median }(I Q R) \\
4 \cdot 5(1-7 \cdot 5)\end{array}$ & $\begin{array}{l}\text { Median (IQR) } \\
4 \cdot 5(3-7 \cdot 5)\end{array}$ & $\begin{array}{l}H \\
0.94\end{array}$ & $\stackrel{p}{\text { NS }}$ \\
\hline
\end{tabular}

$\mathrm{IQR}=$ Interquartile range, $\mathrm{df}=$ degrees of freedom, $\mathrm{H}=\mathrm{Kruskal}-\mathrm{W}$ allis $\mathrm{H}$ statistic

$\star$ Rest 2 and ice results are compared using paired $t$ test and Wilcoxon signed rank test, as described in Methods. tANOVA, as described in Methods. 
TABLE III Effect of stress on amplitude, duration, and propagation velocity of oesophageal contractions and resting lower oesophageal sphincter pressure

(A) Summary statistics for the results for each variable at rest and during stress for all 60 patients ${ }^{\star}$

\begin{tabular}{|c|c|c|c|c|}
\hline & $\begin{array}{l}\text { Rest } \\
\text { Mean (SEM) }\end{array}$ & $\begin{array}{l}\text { Stress } \\
\text { Mean (SEM) }\end{array}$ & $\mathrm{t}(d f, 59)$ & $p$ \\
\hline $\begin{array}{l}\text { Amplitude }(\mathrm{mm} \mathrm{Hg}) \\
\text { Duration }(\mathrm{sec}) \\
\text { Propagation velocity }(\mathrm{cm} / \mathrm{sec}) \\
\text { Lower oesophageal sphincter pressure }\end{array}$ & $\begin{array}{l}\text { Rest } 1 \\
70 \cdot 7(3 \cdot 9) \\
3 \cdot 2(0 \cdot 10) \\
2 \cdot 2(0 \cdot 15)\end{array}$ & $\begin{array}{l}\text { Stroop } \\
73 \cdot 4(4 \cdot 4) \\
3 \cdot 3(0 \cdot 15) \\
2 \cdot 4(0 \cdot 15)\end{array}$ & $\begin{array}{l}1.73 \\
1.30 \\
1.98\end{array}$ & $\begin{array}{l}\text { NS } \\
\text { NS } \\
\text { NS }\end{array}$ \\
\hline (mm Hg) & $16 \cdot 6(1 \cdot 0)$ & $17 \cdot 7(1 \cdot 0)$ & 1.91 & NS \\
\hline $\begin{array}{l}\text { Amplitude }(\mathrm{mm} \mathrm{Hg}) \\
\text { Duration }(\mathrm{sec}) \\
\text { Propagation velocity }(\mathrm{cm} / \mathrm{sec}) \\
\text { Lower oesophageal sphincter pressure }\end{array}$ & $\begin{array}{l}\text { Rest } 2 \\
74 \cdot 2(4 \cdot 1) \\
3 \cdot 5(0 \cdot 10) \\
2 \cdot 1(0 \cdot 14)\end{array}$ & $\begin{array}{l}\text { Ice } \\
74 \cdot 8(4 \cdot 2) \\
3 \cdot 4(0 \cdot 09) \\
2 \cdot 0(0 \cdot 13)\end{array}$ & $\begin{array}{r}0 \cdot 28 \\
-1 \cdot 16 \\
-0 \cdot 24\end{array}$ & $\begin{array}{l}\text { NS } \\
\text { NS } \\
\text { NS }\end{array}$ \\
\hline (mm Hg) & $18 \cdot 2(0.9)$ & $18 \cdot 2(0 \cdot 7)$ & $0 \cdot 12$ & NS \\
\hline
\end{tabular}

(B) Comparison of the delta values (differences between the results for Stress and Rest) for each group $\dagger$

\begin{tabular}{|c|c|c|c|c|c|}
\hline & $\begin{array}{l}\text { Oesophagitis } \\
\text { Mean (SEM) }\end{array}$ & $\begin{array}{l}\text { pH+ } \\
\text { Mean (SEM) }\end{array}$ & $\begin{array}{l}\text { pH- } \\
\text { Mean (SEM) }\end{array}$ & $F(d f, 2,57)$ & $p$ \\
\hline $\begin{array}{l}\text { Stroop } \\
\text { Amplitude (mm } \mathrm{Hg}) \\
\text { Duration }(\mathrm{sec}) \\
\text { Propagation velocity }(\mathrm{cm} / \mathrm{sec}) \\
\text { Lower oesophageal sphincter pressure } \\
\quad(\mathrm{mm} \mathrm{Hg})\end{array}$ & $\begin{array}{r}-1.0(2.3) \\
0.0(0.1) \\
0.2(0.2) \\
\\
0.6(0.8)\end{array}$ & $\begin{array}{l}4.7(2.8) \\
0.1(0.1) \\
0.4(0.2) \\
0.8(0.6)\end{array}$ & $\begin{array}{l}4.5(3.1) \\
0.2(0.1) \\
0.1(0.2) \\
\\
1.8(1.4)\end{array}$ & $\begin{array}{l}1.44 \\
0.56 \\
0.98 \\
\\
0.47\end{array}$ & $\begin{array}{l}\text { NS } \\
\text { NS } \\
\text { NS } \\
\text { NS }\end{array}$ \\
\hline $\begin{array}{l}\text { Ice } \\
\text { Amplitude (mm } \mathrm{Hg}) \\
\text { Duration }(\mathrm{sec}) \\
\text { Propagation velocity }(\mathrm{cm} / \mathrm{sec}) \\
\text { Lower oesophageal sphincter pressure } \\
\quad \text { (mm Hg) }\end{array}$ & $\begin{array}{r}-2.2(3.0) \\
-0.1(0.1) \\
0.1(0.2) \\
\\
0.6(0.8)\end{array}$ & $\begin{array}{r}2.5(3.0) \\
-0.2(0.2) \\
0.0(0.1) \\
-0.4(1.0)\end{array}$ & $\begin{array}{r}1.2(3.6) \\
0.0(0.1) \\
-0.1(0.2) \\
0.0(1.0)\end{array}$ & $\begin{array}{l}0.56 \\
1.10 \\
0.30 \\
\\
0.28\end{array}$ & $\begin{array}{l}\text { NS } \\
\text { NS } \\
\text { NS } \\
\text { NS }\end{array}$ \\
\hline
\end{tabular}

$\mathrm{df}=$ degrees of freedom. ${ }^{\star}$ Results compared by paired $t$ test. †ANOVA.

gender influences at least the haemodynamic response to laboratory stress. ${ }^{17}$ Although currently published studies on the oesophageal response to stress have not reported any difference between males and females, none have set out to address this issue a priori. It is possible, therefore, that the significant increase in simultaneous contractions could be a gender related response. A second possible mechanism for the link between oesophagitis and stress response could be that by inducing simultaneous contractions, stress may aggravate reflux, a delay in the clearance of acid from the oesophagus leading to oesophagitis. Thirdly, it could be argued that the oesophageal response of this

TABLE IV Effect of stress on percentage of non-peristaltic waves

(A) Summary statistics for the results of each variable at rest and during stress for all 60 patients ${ }^{\star}$

\begin{tabular}{|c|c|c|c|c|}
\hline & $\begin{array}{l}\text { Rest } \\
\text { Median }(I Q R) \\
(\%)\end{array}$ & $\begin{array}{l}\text { Stress } \\
\text { Median (IQR) } \\
(\%)\end{array}$ & $\begin{array}{l}Z \\
(d f, 59)\end{array}$ & $p$ \\
\hline $\begin{array}{l}\text { Non-conducted } \\
\text { Simultaneous }\end{array}$ & $\begin{array}{l}\text { Rest 1 } \\
0(0-8) \\
0(0-8)\end{array}$ & $\begin{array}{l}\text { Stroop } \\
0(0-0) \\
0(0-12)\end{array}$ & $\begin{array}{l}1.57 \\
1.15\end{array}$ & $\begin{array}{l}\text { NS } \\
\text { NS }\end{array}$ \\
\hline $\begin{array}{l}\text { Non-conducted } \\
\text { Simultaneous }\end{array}$ & $\begin{array}{l}\text { Rest 2 } \\
0(0-0) \\
0(0-9)\end{array}$ & $\begin{array}{l}\text { Ice } \\
0(0-0) \\
3(0-16)\end{array}$ & $\begin{array}{l}0.44 \\
2.23\end{array}$ & $\begin{array}{l}\text { NS } \\
0.026\end{array}$ \\
\hline
\end{tabular}

(B) Comparison of the delta values (differences between Stress and Rest) for each group $\dagger$

\begin{tabular}{|c|c|c|c|c|c|}
\hline & $\begin{array}{l}\text { Oesophagitis } \\
\text { Median (IQR) } \\
(\%)\end{array}$ & $\begin{array}{l}\text { pH+ } \\
\text { Median (IQR) } \\
\text { (\%) }\end{array}$ & $\begin{array}{l}p H- \\
\text { Median }(I Q R) \\
(\%)\end{array}$ & $H$ & $p$ \\
\hline $\begin{array}{l}\text { Stroop } \\
\text { Non-conducted } \\
\text { Simultaneous }\end{array}$ & $\begin{array}{l}0(0-4 \cdot 5) \\
0(0-14)\end{array}$ & $\begin{array}{l}0(0-0) \\
0(0-0)\end{array}$ & $\begin{array}{l}0(-4 \cdot 5-0) \\
0(0-4 \cdot 2)\end{array}$ & $\begin{array}{l}2 \cdot 82 \\
1.54\end{array}$ & $\begin{array}{l}\text { NS } \\
\text { NS }\end{array}$ \\
\hline $\begin{array}{l}\text { Ice } \\
\text { Non-conducted } \\
\text { Simultaneous }\end{array}$ & $\begin{array}{l}0(0-0) \\
6(0-11)\end{array}$ & $\begin{array}{l}0(0-0) \\
0(0-2)\end{array}$ & $\begin{array}{l}0(0-0) \\
0(-9-+2)\end{array}$ & $\begin{array}{l}0.42 \\
7 \cdot 15\end{array}$ & $\begin{array}{l}\text { NS } \\
0.028 \ddagger\end{array}$ \\
\hline
\end{tabular}

group is different because they have oesophagitis and that the inflammation facilitates the occurrence of abnormal simultaneous waves in response to stress.

Some studies in healthy volunteers and patients with unexplained chest pain ${ }^{9}$ or irritable bowel syndrome ${ }^{18}$ failed to show an increase in non-peristaltic waves in response to stressors. These studies did not, however, document a significant change in cardiovascular responses to the stressors applied.

In the patients with oesophagitis in this study, the median increase in simultaneous waves during the cold pressor test was $6 \%-$ that is, approximately 1 in 20 contractions were simultaneous in nature during stress. Seven of the 20 patients with oesophagitis had a $10-30 \%$ increase in simultaneous waves - for example, a change from $0 \%$ simultaneous waves at rest to $20 \%$ during cold pressor test, a change which was $90 \%$ specific for the oesophagitis group. It is possible that this degree of dysmotility could be regarded as clinically significant, especially since the definition of diffuse oesophageal spasm only requires the presence of more than one simultaneous wave during 10 wet swallows. ${ }^{15}$

Certain methodological issues must be addressed in the interpretation of this study. Firstly, before commenting on the oesophageal response, it is important to show that the stressor was effective. In this current study, there were highly significant changes in subjective and cardiovascular autonomic responses to stress. The chosen stressors were therefore effective, a finding which is not universal among the other studies which used these and other stressors. ${ }^{8918}$

Secondly, how appropriate were the chosen stressors? The Stroop colour-word test and the 
cold pressor test were deliberately selected to provide a psychological and a primarily physical stressor. Both have been widely used and have been extensively validated. ${ }^{121319}$ However, the period of stress lasted less than 10 minutes in each case, producing a brief, intense focus. A more useful stressor might be one which is of greater duration, paralleling the chronic stress experienced in the community. ${ }^{20}$ With the new technology of ambulatory manometry, it is now feasible to achieve a more long term measurement of oesophageal motility. ${ }^{21} 22$ It might also be more appropriate to chose stressors which better reflect day to day events than the immersion of a hand in ice. Public speaking, video arcade games, driving in heavy traffic and sleep deprivation have all been used for this purpose. ${ }^{23} 24$

Thirdly, were the chosen oesophageal variables meaningful? Amplitude, duration, and propagation of velocity of peristaltic contractions and the percentage of non-peristaltic waves were the measurements used in all studies of the oesophageal stress response to date. ${ }^{7-9} 18$ Assessment of changes in amplitude, duration and velocity of propagation of peristaltic contractions may have limited clinical relevance. For example, it has been shown that any peristaltic wave with a contraction amplitude of greater than $40 \mathrm{~mm} \mathrm{Hg}$ is effective at clearing the oesophagus of a bolus. ${ }^{16}$ An increase or decrease of $10 \mathrm{~mm} \mathrm{Hg}$ while remaining above this threshold is therefore not going to alter oesophageal function. However, non-peristaltic waves have been shown to impair oesophageal function and correspond to recognised motility disorders. ${ }^{15} 16$ They are, therefore, more clinically relevant when present. Recently, devices have been introduced which can measure oesophageal traction force. ${ }^{2526}$ These may be more useful instruments in assessing the oesophageal response to stress.

Fourthly, the order of stressors in this study was not randomised. It is possible that the first stressor (Stroop) sensitised the oesophagus, potentiating a response to the second stressor (ice). Such an association has been shown during intraoesophageal balloon distension, prior acid infusion resulting in pain at lower balloon volumes compared with prior saline infusion. ${ }^{27} \mathrm{~A}$ further study randomising the order of the stress periods would be required to address this issue. Regardless of whether the cold pressor test alone or in conjunction with prior sensitisation caused the effect, there was a significant increase in simultaneous waves in response to the ice stressor among patients with oesophagitis.

Sixty four per cent of patients with reflux symptoms believe that stress is a factor. Despite this, no significant alteration of any aspect of oesophageal motility could be shown for most patients with GORD in our study. Other mechanisms by which stress could exacerbate reflux symptoms must be considered. A recent study reported that while cold stress reduced the resistance to flow across the gastro-oesophageal junction, it also reduced gastric tone maintaining the equilibrium between forces for reflux and for defence. ${ }^{28}$ It has also been shown recently that although stressful tasks increased the reporting of reflux symptoms, they did not increase the degree of acid reflux. ${ }^{29}$ A study of LOS function in the postprandial period in healthy volunteers described a reduced number of transient lower oesophageal sphincter relaxations and a reduction in reflux in response to stress. ${ }^{30}$ Thus, neither measures of LOS function (transient LOS relaxations, resting LOS tone, and gastro-oesophageal junction resistance) nor oesophageal acid exposure seem to be increased by stressors. The most likely mechanism by which stressful events increase the reporting of reflux symptoms is by making the patient more aware of the reflux that is occurring, whether in pathological or physiological proportions. Bradley et al have reported that while stressful tasks did increase the reporting of reflux symptoms, this was primarily true among those who were anxious and who displayed 'gastrointestinal susceptibility'. ${ }^{31}$ The symptom reporting was independent of the degree of oesophageal acid exposure. This interaction between psychological factors and stress has also been noted in other settings, such as the perception of somatic pain in substance abusers and the gastric acid secretory response to hypnotically induced emotions, both of which are increased in anxious patients. ${ }^{32} 33$

In conclusion, acute stressors did not induce significant changes in oesophageal motility in patients with GORD but no oesophagitis. However, there was a significant increase in simultaneous waves during cold pressor stress in patients with oesophagitis. Whether this is a factor which predisposes them to oesophagitis, or the oesophagitis-related inflammation causes the abnormal response, is not yet known.

We are indebted to Sister Elizabeth Crawford for her help in carrying out these experiments. During the course of this research, BTJ was in receipt of research fellowship from the Royal Victoria Hospital, Belfast and the Ulster Hospital, Dundonald.

1 Johnston BT, McFarland RJ, Collins JSA, Love AHG Predictors of oesophageal acid exposure in gastro-
oesophageal reflux disease. Eur $\mathcal{F}$ Gastroenterol Hepatol 1993; 5: 875-9.

2 Johnsson F, Joelsson B, Gudmundsson K. Determinants of gastro-oesophageal reflux and their inter-relationships. of gastro-oesophageal reflux

3 De Meester TR, Wang CI, Wernly JA, Pellegrini CA, Little AG, Klementschitsch P, et al. Technique, indications and clinical use of 24 hour esophageal $\mathrm{pH}$ monitoring. f Thorac Cardiovasc Surg 1980; 79: 656-70.

4 Johansson K-E, Ask P, Boeryd B, Fransson S-G, Tibbling $\mathrm{L}$. Oesophagitis, signs of reflux and gastric acid secretion in patients with symptoms of gastro-oesophageal reflux disease. Scand $\mathcal{f}$ Gastroenterol 1986; 21: 837-47.

5 Anonymous. $A$ Gallup survey on heartburn across America. Princeton, NJ: The Gallup Organisation Inc, 1988.

6 Wolf S, Almy TP. Experimental observations on cardiospasm in man. Gastroenterology 1949; 13: 401-21.

7 Ayres RCS, Robertson DAF, Naylor K, Smith CL. Stress and oesophageal motility in normal subjects and in patients with irritable bowel syndrome. Gut 1989; 30: Stacher G, Schmierer G, Landgraf M. Tertiary esophageal contractions evoked by acoustical stimuli. Gastroenterology 1979; 77: 49-54.

9 Anderson KO, Dalton GB, Bradley LA, Richter JE. Stress induces alteration of esophageal pressures in healthy volunteers and non-cardiac chest pain patients. Dig Dis Sci 1989; 34: 83-91.

10 Little AG, De Meester TR, Kirchner PT, O'Sullivan GC, Skinner DB. Pathogenesis of esophagitis in patients with gastroesophageal reflux. Surgery 1980; 88: 101-7. 
11 Johnston BT, McFarland RJ, Collins JSA, Love AHG. The symptom index: a useful marker of gastro-oesophageal symptom index: a useful marker of gastro-
reflux disease. $B r f$ Surg 1992; 79: 1054-5.

12 Tulen JHM, Moleman P, Van Steenis HG, Boomsma F. Characterisation of stress reactions to the Stroop color word test. Pharmacol Biochem Behav 1989; 32: 9-15.

13 Lovallo W. The cold pressor test and autonomic function: a review and integration. Psychophysiology 1975; 12: 268-82.

14 DeVault KR, Castell JA, Castell DO. How many swallows are required to establish reliable esophageal peristaltic parameters in normal subjects? An on-line computer analysis. Am $\mathcal{F}$ Gastroenterol 1987; 82: 754-7.

15 Richter JE. Diffuse esophageal spasm. In: Castell DO, Castell JA, eds. Esophageal motility testing. 2nd ed. Castell JA, eds. Esophageal motility testin

16 Kahrilas PJ, Dodds WJ, Hogan WJ. Effect of peristaltic dysfunction on esophageal volume clearance. Gastroenterology 1988; 94: 73-80.

17 Allen MT, Stoney CM, Owens JF, Matthews KA. Hemodynamic adjustments to laboratory stress: the influence of gender and personality. Psychosom Med 1993; 55: 505-17.

18 Soffer EE, Scalabrini P, Pope CE 2nd, Wingate DL. Effect of stress on oesophageal motor function in normal subjects and in patients with the irritable bowel syndrome. Gut 1988; 29: 1591-4.

19 Lacey JI, Lacey BC. The law of initial value in the longitudinal study of autonomic constitution: Reproducibility of autonomic responses and response patterns over a four autonomic responses and response patterns over
year interval. Ann NY Acad Sci 1962; 38: 1257-90.

20 McRae S, Younger K, Thompson DG, Wingate DL. Sustained mental stress alters human jejunal motor activity. Gut 1982; 23: 404-9.

21 Emde C, Armstrong D, Castiglione F, Cilluffo T, Riecken EO, Blum AL. Reproducibility of long-term ambulatory esophageal combined $\mathrm{pH} /$ manometry. Gastroenterology 1991; 100: 1630-7.

22 Eypasch EP, Stein HJ, De Meester TR, Johansson K-E, Barlow AP, Schneider GT. A new technique to define and clarify esophageal motor disorders. Am f Surg 1990; 159: 144-51.
23 Lepore SJ, Allen KA, Evans GW. Social support lowers cardiovascular reactivity to an acute stressor. Psychosom Med 1993; 55: 518-24.

24 Valori RM, Kumar D, Wingate DL. Effects of different types of stress and of 'prokinetic' drugs on the control of the fasting motor complex in humans. Gastroenterology 1986; 90: 1890-900.

25 Williams D, Thompson DG, Marples $M$, Heggie L, O'Hanrahan $\mathrm{T}$, Mani $\mathrm{V}$, et al. Identification of an abnormal esophageal clearance response to intraluminal distension in patients with esophagitis. Gastroenterology 1992; 103: 943-53.

26 Williams D, Thompson DG, Heggie $L$, O'Hanrahan $T$, Bancewicz J. Esophageal clearance function following treatment of esophagitis. Gastroenterology 1994; 106: treatment

27 Mehta AJ, De Caestecker JS, Camm AJ, Northfield TC. Sensitisation to painful distension and abnormal sensory perception in the esophagus. Gastroenterology 1995; 108: 311-9.

28 Zacchi $P$, Mearin F, Malagelada JR. Effect of experimental cold pain stress on gastroesophageal junction. Dig Dis $\mathrm{Sci}$ 1994; 39: 641-7.

29 McDoland-Haile J, Bradley LA, Bailey MA, Schan CA, Richter JE. Relaxation training reduces symptom reports and acid exposure in patients with gastroesophageal reflux disease. Gastroenterology 1994; 107: 61-9.

30 Penagini $R$, Bartesaghi B, Bianchi PA. Effect of cold stress on postprandial lower esophageal sphincter competence on postprandial lower esophageal sphincter competence and gastroesophageal

31 Bradley LA, Richter JE, Pulliam TJ, Haile JMcD, Scarinci IC, Schan CA, et al. The relationship between stress and symptoms of gastroesophageal reflux: the influence of psychological factors. Am $\mathcal{F}$ Gastroenterol 1993; 88: 11-9.

32 Malow RM, West JA, Sutker PB. Anxiety and pain response changes across treatment: Sensory decision analysis. Pain 1989; 38: 35-44.

33 Eichhorn R, Tracktir J. The relationship between anxiety, hypnotically induced emotions and gastric secretion. Gastroenterology 1955; 29: 422-31. 